\title{
EVALUATION OF THE MECHANICAL PROPERTIES AND DURABILITY OF CEMENT MORTARS CONTAINING ALGERIAN METAKAOLIN
}

\author{
"KAMEL SALHI*, BOUZIDI MEZGHICHE** \\ *Civil Engineering Department, University of Souk Ahras, Algeria \\ **Research Laboratory Civil Engineering, University of Biskra, Algeria \\ \#E-mail: salhi2009@yahoo.fr
}

Submitted September 26, 2016; accepted November 16, 2016

\begin{abstract}
Keywords: Compressive strength, Metakaolin, Shrinkage, Swelling, Sulfate attack
This study shows the results of an examination on the use of metakaolin (MK) as an additional cementing material to improve the mechanical properties and durability of cement paste and mortar. For MK replacement levels were employed in the study: $5 \%, 10 \%, 15 \%$ and $20 \%$ by weight of the Portland cement used. Three series of paste mixture were designed at three water-cementations materials $(w / \mathrm{cm})$ ratios of $0.25,0.30$ and 0.40 . The performance characteristics of the paste and mortars were evaluated by measuring compressive, drying shrinkage, and swelling. The sulfate resistance of the mortar was also examined in the present study. The results showed that the inclusion of MK exceptionally reduced the drying shrinkage strain and excellent performance of swelling, but increased the strengths of the cement paste in differing degrees, depending principally on the MK substitution levels, w/cm ratio, and age of testing. It was also affirmed that the MK provided an excellent improvement in resistance to the sulfate sodium $\left(\mathrm{Na}_{2} \mathrm{SO}_{4}\right)$, especially for the high-level MK replacement.
\end{abstract}

\section{INTRODUCTION}

Concrete Portland the cement will most usually remain the building material uses in the world [1].The diversity of its application and its intrinsic qualities make that its request is in constant growth. It is by definition a material is composed, constitutes cement, aggregates and of water primarily; however, Cement industry was responsible for $5-8 \%$ of the emissions of carbon dioxide gas in the world [2-3].The cement industry not only released carbon dioxide gas but also generated $\mathrm{SO}_{3}$ and $\mathrm{NO}_{\mathrm{x}}$ gasses which caused the greenhouse effect and incurred severe environmental impacts [4-5].

A promising option for lowering costs and environmental impact of concrete is to use blended cement which reduces the clinker content in the cement by replacing it with supplementary cementitious materials (SCMs). The most commonly used SCM's come from natural sources or by-products of other industries such as blast furnace slag, silica fume, fly ash, rice husk ash, etc. [6-8]. Supplementary cementing materials are siliceous materials or aluminous silico-aluminous presenting a reactive or amorphous phase [9-11] they can have hydraulic properties i.e. they hydrate in an independent way in contact with water. They can also present pozzolanic properties i.e. in the presence of water; the addition reacts with the portlandite $\mathrm{Ca}(\mathrm{OH})_{2}$ to form $\mathrm{C}-\mathrm{S}-\mathrm{H}$ [12]. This reaction is particularly interesting since the portlandite, which contributes little to resistance and the high amount of portlandite in cement pastes is reported to cause instability of concrete when it is exposed the acid solution as well as high temperatures $[6,13,14]$.

In recent works have shown that the addition of MK greatly influenced the mechanical and durability properties of concrete, for example, resistance concrete at elevated temperature [26], and corrosion resistance concrete [27]. In particular, concerning resistance to sulfate attack the test results have shown that the expansion has systematically decrease with increasing content $\mathrm{MK}$ for both types of cement used high and low $\mathrm{C}_{3} \mathrm{~A}$ content [28]. Other study have showed that the metakaolin decrease not only the quantity of free lime, but also those of aluminates available in the interstitial solution. Combined with that, the densification of the cement matrix by the metakaolin led to the reduction in its permeability and its diffusivity significantly increases the resistance of the concrete to the migration of the ions sulfates [29]. Moreover Bai et al. [30] compared the expansion of mortars $(\mathrm{w} / \mathrm{b}=0.5)$ containing various rates of substitution in metakaolin or fly-ashes, immersed in a sodium sulfates solution (sulfate concentration of $\left.16 \mathrm{~g} \cdot \mathrm{l}^{-1}\right)$. At one year, the mortars containing pozzolans almost do not present dimensional variations, whereas the mortar which contained $100 \%$ cement Portland cement expanded in the following way. The mortar which has the best resistance is that which contained $15 \%$ of metakaolin. 
The principal objective of the present work is to study the effectiveness MK used at various replacements, levels $5 \%, 10 \%, 15 \%$, and $20 \%$ were considered by weight of cement on the performance of the cement and mortar concerning compressive and drying shrinkage, swelling and sulfate resistance.

\section{EXPERIMENTAL}

Materials and Sample Preparation

The cementitious materials used in this study were ordinary Portland cement (OPC) was conforming to the European standard EN 197-1. The MK used in this

Table 1. Properties of Portland cement and Metakaolin used.

\begin{tabular}{|c|c|c|}
\hline Item & Portland cement & Metakaolin \\
\hline $\mathrm{SiO}_{2}(\%)$ & 20.16 & 53.05 \\
\hline $\mathrm{Al}_{2} \mathrm{O}_{3}(\%)$ & 4.24 & 37.15 \\
\hline $\mathrm{Fe}_{2} \mathrm{O}_{3}(\%)$ & 3.89 & 3.12 \\
\hline $\mathrm{CaO}(\%)$ & 61.79 & 0.22 \\
\hline $\mathrm{MgO}(\%)$ & 1.24 & 0.55 \\
\hline $\mathrm{SO}_{3}(\%)$ & 2.12 & 0.02 \\
\hline $\mathrm{Na}_{2} \mathrm{O}(\%)$ & - & 0.23 \\
\hline $\mathrm{K}_{2} \mathrm{O}(\%)$ & 0.42 & - \\
\hline Insoluble residue (\%) & 0.64 & - \\
\hline Loss on ignition (\%) & - & 1.4 \\
\hline Free lime $(\%)$ & 0.30 & - \\
\hline $\mathrm{C}_{3} \mathrm{~S}(\%)$ & 52.48 & - \\
\hline $\mathrm{C}_{2} \mathrm{~S}(\%)$ & 13.86 & - \\
\hline $\mathrm{C}_{3} \mathrm{~A}(\%)$ & 4.65 & - \\
\hline $\mathrm{C}_{4} \mathrm{AF}(\%)$ & 11.83 & - \\
\hline Specific gravity $\left(\mathrm{g} \cdot \mathrm{cm}^{-3}\right)$ & 3.15 & 2.52 \\
\hline Specific surface area $\left(\mathrm{m}^{2} \cdot \mathrm{kg}^{-1}\right)$ & 3020 & 4500 \\
\hline
\end{tabular}

study has pink color and obtained by heat treatement of Algerian kaolin, at $850^{\circ} \mathrm{C}$ for 3 hours .The chemical and physical properties of these materials are given in Table 1. Stander sand was employed for manufacturing mortar specimens. The fine aggregate was less than $4 \mathrm{~mm}$. The specific gravity, absorption and fineness modulus of the fine aggregate were $2.63,0.80 \%$ and 2.53 , respectively. To obtain a suitable workability, a superplasticizer MEDAPLAST-SP40, (sulfonated polynaphthalene type) with a solid content of $40 \%$ by weight was used in all mortars.

The water employed for manufacturing paste and mortar specimens is drinking water that contains little sulfate and having a temperature of $20 \pm 2{ }^{\circ} \mathrm{C}$. Its quality conforms to the requirements of standard NFP 18-404.

Three series of paste mixes were prepared at the $\mathrm{w} / \mathrm{b}$ ratios of $0.25,0.30$ and 0.4 . Each series included $4 \mathrm{MK}$ mixes with $5 \%, 10 \%, 15 \%$ and $20 \%$ metakaolin and a control mix without any mineral admixture. The mortar mixes had a proportion of 1 binder:3Sand. The binder consisted of cement and metakaolin. The cement was formulated varying the replacement of MK. The water binder (w/b) ratio was kept constant at 0.5 . MK was used as a replacement of cement on a weight to weight basis. The details of the Paste and mortar mixtures are given in Table 2 and 3. The paste mixtures were prepared in the laboratory using a pan mixer. Cubes of $25 \times 25 \times 25 \mathrm{~mm}$ in dimension were cast in the steel mould and compacted on a vibrating table. The cubes were removed from the moulds $24 \mathrm{~h}$ after casting. The mortar mixtures were prepared in the laboratory using a pan mixer, and were cast in prismatic steel mould of $40 \times 40 \times 160 \mathrm{~mm}$ and $25 \times 25 \times 285 \mathrm{~mm}$ in dimension and compacted on a vibrating table the prism were removed from the moulds $24 \mathrm{~h}$ after casting.

Table 2. Mixture proportions of the paste.

\begin{tabular}{|c|c|c|c|c|c|}
\hline \multirow{2}{*}{ Mixture code } & \multirow{2}{*}{$\mathrm{W} / \mathrm{b}$ ratio } & \multirow{2}{*}{ Cement type } & \multicolumn{3}{|c|}{ Cementitious materials (\%) } \\
\hline & & & Clinker & Gypsum & $\mathrm{MK}$ \\
\hline M0 & 0.25 & & & & \\
\hline M1 & 0.30 & $100 \%$ OPC & 95 & 5 & 0 \\
\hline M2 & 0.40 & & & & \\
\hline M3 & 0.25 & & & & \\
\hline M4 & 0.30 & $95 \% \mathrm{OPC}+5 \% \mathrm{MK}$ & 90 & 5 & 5 \\
\hline M5 & 0.40 & & & & \\
\hline M6 & 0.25 & & & & \\
\hline M7 & 0.30 & $90 \% \mathrm{OPC}+10 \% \mathrm{MK}$ & 85 & 5 & 10 \\
\hline M8 & 0.40 & & & & \\
\hline M9 & 0.25 & & & & \\
\hline M10 & 0.30 & $85 \% \mathrm{OPC}+15 \% \mathrm{MK}$ & 80 & 5 & 15 \\
\hline M11 & 0.40 & & & & \\
\hline M12 & 0.25 & & & & \\
\hline M13 & 0.30 & $80 \% \mathrm{OPC}+20 \% \mathrm{MK}$ & 75 & 5 & 20 \\
\hline M14 & 0.40 & & & & \\
\hline
\end{tabular}


Table 3. Mixture proportioning of the mortar.

\begin{tabular}{lccccc}
\hline Mixture & $\begin{array}{c}\text { Replacement } \\
\text { levels of MK } \\
(\%)\end{array}$ & $\begin{array}{c}\text { Cement } \\
(\mathrm{g})\end{array}$ & $\begin{array}{c}\text { MK } \\
(\mathrm{g})\end{array}$ & $\begin{array}{c}\text { Water }) \\
(\mathrm{g})\end{array}$ & $\begin{array}{c}\text { Sand } \\
(\mathrm{g})\end{array}$ \\
\hline MK0 & 0 & 450.0 & 0 & 225 & 1350 \\
MK5 & 5 & 427.5 & 22.5 & 225 & 1350 \\
MK10 & 10 & 405.0 & 45.0 & 225 & 1350 \\
MK15 & 15 & 382.5 & 67.5 & 225 & 1350 \\
MK20 & 20 & 360.0 & 90.0 & 225 & 1350 \\
\hline
\end{tabular}

\section{Mechanical Strength Testing}

To evaluate the strength characteristics, of the plain and MK paste the compression test was carried out on the cube $25 \mathrm{~mm}$ cubes were used for the determination of compressive strength. The compression load was applied using a controls compression machine with $2000 \mathrm{KN}$ capacity, at the rate of $2400 \mathrm{~N} / \mathrm{s}$ according to ASTM C39. The strength measurements of paste were performed at the ages of 7, 28 and 90 days. Three specimens were used for each measurement age

\section{Drying Shrinkage and Swelling Tests}

Drying shrinkage measurements were conducted in agreement with NF P15-433. The length change was measured using a dial gauge extensometer with a $160 \mathrm{~mm}$ gage length. The measurements of drying shrinkage were carried out every $24 \mathrm{~h}$ for the first three weeks and then three times a week. Variations in the drying shrinkage strain were monitored during the 120-day drying period (at $23 \pm 2^{\circ} \mathrm{C}$ and $50 \pm 5 \%$ relative humidity). The measurements of swelling started at about $24 \mathrm{~h}$ after casting, after specimens were demoulded and stored in water, and the average of three prism specimens were used for each property.

\section{Sulfate Attack Tests}

For the sulfate attack tests, the mortars specimens were immersed in $5 \%$ sodium sulfate $\left(\mathrm{Na}_{2} \mathrm{SO}_{4}\right)$ at laboratory temperature $\left(23 \pm 2{ }^{\circ} \mathrm{C}\right)$. The sulfate solution was renewed every 7 days. The sulfate attack was evaluated through the measurement of the expansion in agreement with ASTM C-1012 on prismatic specimens measuring $25 \times 25 \times 285 \mathrm{~mm}$.

\section{RESULTS AND DISCUSSION}

\section{Compressive strengths}

Figures 1, 2 and 3, show the influence of metakaolin content on compressive strengths of the paste at 7, 28, and 90-day for various water-binder ratios W/ (C+MT). At the short- term and in particularly to 7 days, It was observed that partial replacement of cement by $10 \%$

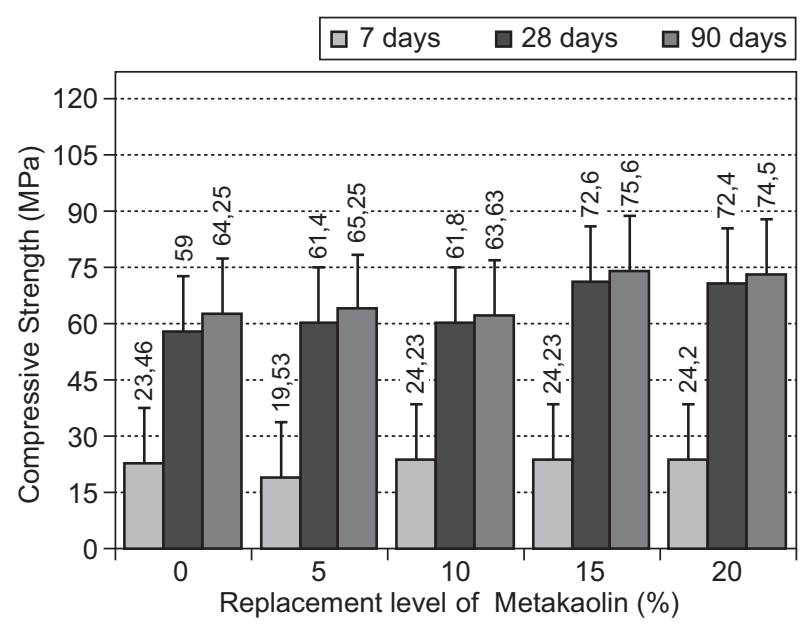

Figure 1. Effect of metakaolin (MK) on the compressive strength development of pastes $\mathrm{W} /(\mathrm{C}+\mathrm{MT})=0.40$.

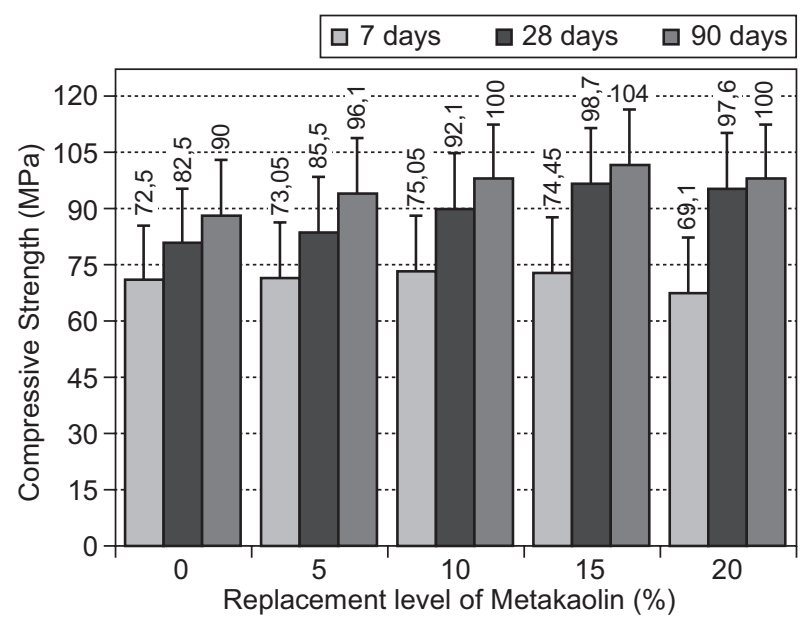

Figure 2. Effect of metakaolin (MK) on the compressive strength development of pastes $\mathrm{W} /(\mathrm{C}+\mathrm{MT})=0.30$.

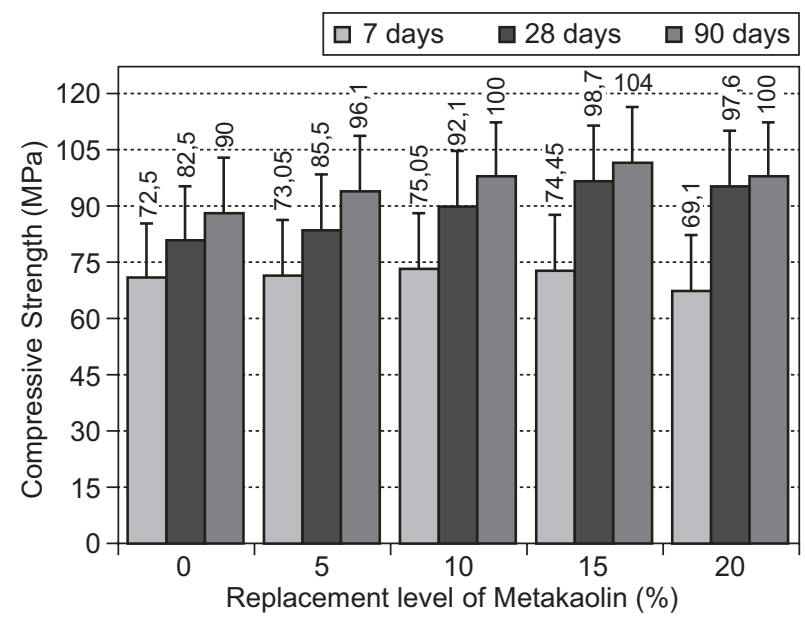

Figure 3. Effect of metakaolin (MK) on the compressive strength development of pastes $\mathrm{W} /(\mathrm{C}+\mathrm{MT})=0.25$. 
metakaolin presented the highest strengths which exceed that of reference binder without metakaolin, and this whatever the water-binder ratios $\mathrm{W} /(\mathrm{C}+\mathrm{MT})$. As an example, for the water to binder ratio $\mathrm{W} /(\mathrm{C}+\mathrm{MT})=$ $=0.25,0.30$ and 0.40 it reached a value max of strength 88.50 $\mathrm{MPa}, 75.05 \mathrm{MPa}$, and 26.45 $\mathrm{MPa}$ respectively. The rate of increase in strength is about $7.53 \%, 3.5 \%$ and $3.9 \%$ respectively compared to the binder of reference without metakaolin. Moreover, it is noted that the increase of the cement content by substitution of metakaolin beyond this proportion $10 \%$ to entrained a slight decrease of the strength. It appears therefore that $10 \%$ MK is the optimum cement substitution by metakaolin at this age. A similar results were found in reference $[23,36]$, showing that the partial substitution of cement by metakaolin generates a compressive strength improvement, the contribution of metakaolin to improve the compressive strength as the combination of three main effects of mineral additions on the properties of cement materials. These effects are: (i) a physical effect, especially to metakaolin particles called "filler effect"; (ii) Physico-chemical effect, that acts on the acceleration of hydration Portland cement which has maximum impact within the first 24 hours; (iii) the chemical effect makes the greatest contribution to strength somewhere between 7 and 14 days [23, 31-34]. These effects act simultaneously and complementarily on improving the mechanical performance of cementitious materials. Moreover in the medium and long-term (28 to 90 days), it is found that replacement of cement by $15 \%$ metakaolin presented the highest strength exceeding that of the binder of reference and greater than the cementitious mixtures containing $5 \%, 10 \%$ and $20 \%$ metakaolin, and this irrespective of the $\mathrm{W} /$ ratio $(\mathrm{C}+\mathrm{MT})$ ratio. For example, it reached a value max of $115 \mathrm{MPa}$ and $120 \mathrm{MPa}$ respectively for 28 and 90 days for water-binder ratio $\mathrm{W} /(\mathrm{C}+\mathrm{MT})=0.25$, the rate of increase in strength is about $26 \%$ and $10 \%$ respectively for 28 and 90 days. The increase, in the content of replacement of cement by metakaolin beyond $15 \%$ results by the dilution effect of the cement $[23,36]$, a slight decrease in strengths but always with strengths being equivalent seeing higher than the binder of reference without metakaolin. So it seems that $15 \%$ is the optimum MK cement substitution by Metakaolin medium and long term. Furthermore, comparing the strength of gain obtained at 28 and 90 days, then that registered in the short-term to 7 days indicates that metakaolin contribution in the development of resistance by their pozzolanic effect is relatively medium-term higher comparing to short-term, prove that the pozzolanic metakaolin reaction is well started at this age. confirms that metakaolin generates higher pozzolanic activity, especially for later ages, this may explain the significant improvement in the strength provided by metakaolin medium and long-term [58, 35]. For the effect, of the water to binder ratio $\mathrm{W} /(\mathrm{C}+\mathrm{MT})$, on the strength development of the mixtures, containing different proportion from metakaolin. It is evident to remark that the reduction of the water to binder ratio $\mathrm{W} /(\mathrm{C}+\mathrm{MT})$ generates an improvement significant of strength and whatever the content of cement substitution by metakaolin. As an example, the reduction of the water to binder ratios $\mathrm{W} /(\mathrm{C}+\mathrm{MT})$ from 0.30 to 0.25 , The rates of improvement of strength for the cement paste without metakaolin and with $5 \%, 10 \%, 15 \%$, and $20 \%$ of metakaolin are of order $15.53 \%, 18.00 \%, 11.50 \%$ and $15.70 \%$, at seven 7 days, respectively. While, the rate of improvement of strength, is of order $17 \%, 15 \%, 15 \%$ and $13 \%$, at 90 days, respectively. That can conclude, that the compressive strength varies inversely with the water to binder ratio $\mathrm{W} /(\mathrm{C}+\mathrm{MT})$ and therefore with the porosity. The reduction in the quantity of water in the paste, with ensuring appropriate consistency generates a strength increase is due to a decrease in volume of capillary pores which contributed accordingly, the increase in strength. A similar results was found in reference [37] shown that compressive strength of cement paste containing different proportion from the sand of dune, is significant increases with the reducing in the water to binder ratio $\mathrm{W} /(\mathrm{C}+\mathrm{MT})$. According to the authors, the improvement of strengths is attributed, to the change of the structure pores entraining thus an increase in the volume of the fine pores to the detriment of the large pores.

\section{Drying shrinkage}

Figure 4 shows the strain developments of the drying shrinkage of control mortar and mortar incorporating various proportions of metakaolin: $5 \%, 10 \%, 15 \%$ and $20 \%$, according to time. From this graph, the following comments can be made. In the short-term ( $\leq 14$ days) it possible to observed for the first time to fast kinetics of the evolution of drying shrinkage up to 14 days and then gradually slow kinetics. In the second time that except for mortar incorporating $20 \%$ of metakaolin,

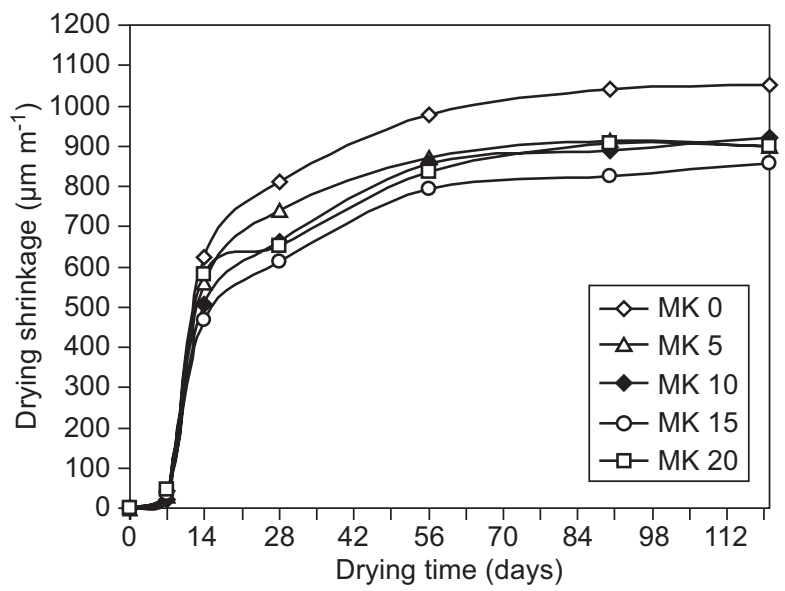

Figure 4. Effect of metakaolin on the early age drying shrinkage of mortar. 
recorded at 7 days of deformation slightly higher to that of control mortar, all mortars, incorporating of metakaolin presenting deformations of drying shrinkage lower than that of control mortar without metakaolin. As an example, at 14 days, incorporation $5 \%, 10 \%$, $15 \%$ and $20 \%$ of metakaolin led have a reduction in the drying shrinkage of order $11 \%, 19 \%, 25 \%$ and $6.75 \%$ respectively compared to the control mortar. In intensity term, It clearly observed, that the mortar incorporating $15 \%$ of metakaolin produces low deformations of the drying shrinkage $\left(468.7 \mu \mathrm{m} \cdot \mathrm{m}^{-1}\right.$ at 14 days $)$, while the mortar is incorporating $10 \%$ of metakaolin also produces low deformations of the drying shrinkage (20.37 $\mu \mathrm{m} \cdot \mathrm{m}^{-1}$ at 7 days). The low values, of deformations of shrinking of the mortars containing metakaolin, are attributed primarily to the effect of filler and pozzolanic metakaolin particles that contribute to refining capillary porosity and to make the material less sensitive to the desiccation, and consequently to decrease its shrinkage. Moreover, the pozzolanic reaction of the metakaolin generates a reduction in interstitial water in the system; therefore less water evaporable will be available during the contraction [38]. what could explain the low values of shrinkage on the other hand, in the medium term 28 days just like at 14 days, all the incorporating mortars of metakaolin develop shrinkage lower than that of control mortar, This observation more illustrates the substantial contribution of the metakaolin in the reduction of drying shrinkage of medium-term.

Between 56 and 120 days, one can also observe that the deformations generated by the drying shrinkage tend to be stabilized, for all the mortars. In terms of intensity of deformation, the mortar incorporating $15 \%$ of metakaolin will develop the shrinkage deformation (793.7 $\mu \mathrm{m} \cdot \mathrm{m}^{-1}$ at 56 days).However, we notice that beyond 56 days the difference between the values of drying shrinkage for the mortars containing metakaolin tends to decrease, reflect a similar effect of the rate of incorporation of metakaolin on the long-term drying shrinkage. As an example, drying shrinkage values is $900 \mu \mathrm{m} \cdot \mathrm{m}^{-1}, 920 \mu \mathrm{m} \cdot \mathrm{m}^{-1}, 856 \mu \mathrm{m} \cdot \mathrm{m}^{-1}$ and $900 \mu \mathrm{m} \cdot \mathrm{m}^{-1}$ for mortars incorporating $5 \%, 10 \%, 15 \%$ and $20 \%$ of metakaolin respectively .while the reference mortar without metakaolin showed a drying shrinkage of about $1052 \mu \mathrm{m} \cdot \mathrm{m}^{-1}$. These results are in perfect agreement with those in reference [38-39] which showing that the drying shrinkage is strongly decreased by the presence of the metakaolin, of approximately $50 \%$ some are the rate of cement substitution by metakaolin. In the same way others study, have finds a reduction shrinkage almost a third after 156 days for $10 \%$ of metakaolin [22]. Others study have shown that the ultrafine additions such as the granulated slag and silica can considerably support on the one hand the hydration of cement and on the other hand the formation of the new hydrates and to increase consequently the quantity of crystal hydrates of ettringite (AFt phase) and of calcium silicate hydrates $(\mathrm{C}-\mathrm{S}-\mathrm{H})$ in cement paste, which offers a denser structure to the hardened concrete and higher strength [40]. This could be possibly the mechanism of action of the additions ultrafine (the granulated slag and silica) reduce the effect of creep and drying shrinkage of the concrete. The whole tendency which this releases from these results is whatever the level replacement of cement by metakaolin the strain developments by the drying shrinkage of the mortar with metakaolin it is in order inferior with that of the mortars containing cement without metakaolin.

\section{Swelling}

Figure 5 shows the evolution of swelling of the mortars studied according to time and rate of incorporation of metakaolin. It is clear to notice that the reference mortar present a higher swelling comparing mortar containing metakaolin, for all ages to study, and so regardless the rate of incorporation of metakaolin. For example, to nearly 90 days of exposure, swelling of values is $124 \mu \mathrm{m} \cdot \mathrm{m}^{-1}, 143 \mu \mathrm{m} \cdot \mathrm{m}^{-1}, 156 \mu \mathrm{m} \cdot \mathrm{m}^{-1}$ and $118 \mu \mathrm{m} \cdot \mathrm{m}^{-1}$ for mortars incorporating $5 \%, 10 \%, 15 \%$ and $20 \%$ of metakaolin respectively, while the reference mortar without metakaolin showed a swelling of about $218 \mu \mathrm{m} \cdot \mathrm{m}^{-1}$. On the other, hand for the incorporation rate of metakaolin effect on swelling. Can be seen as swelling, be proportional to the content of metakaolin. The low swelling values observed in mortars containing metakaolin is attributed to the densification of the matrix as a result of the pozzolanic reaction of metakaolin limit the penetration of water and thus reduces the swelling phenomenon. In fact, the swelling in water is related to the absorption of water by the cement gel water molecules acting against the forces of cohesion and tending to move the gel particles thus creating a more swelling pressure, the intrusion of water reduces tension gel surface, causes by following a small expansion [41]. A similar result was found in reference [50, 51, 52, 53] Who shown a reduction in swelling, with the increasing the level of silica fume according to these study, the

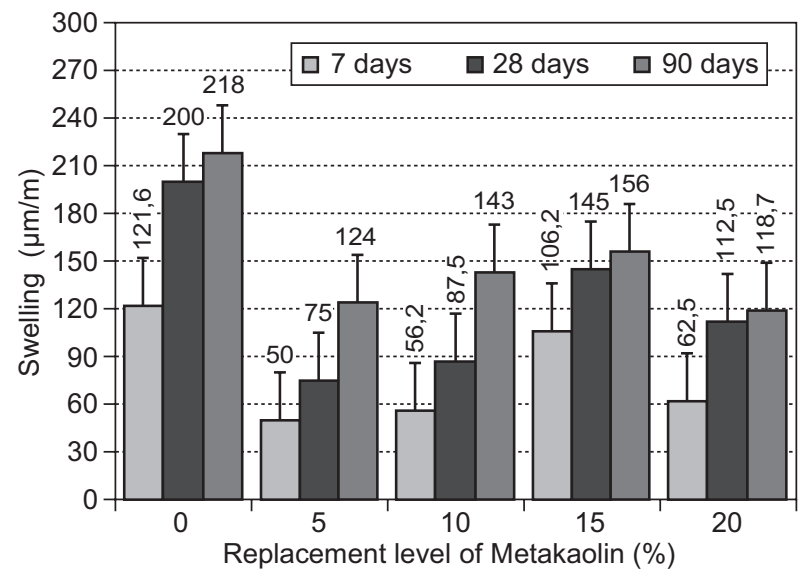

Figure 5. Effect of metakaolin on the early age swelling of mortar. 
decrease in swelling of these types of concretes is related to a reduction in the permeability thus entraining a reduction of the penetration of water. Furthermore, it is remembered that other factors can also cause swelling of cement pastes such as the formation of ettringite and portlandite early hardening cement whose growth pressured the entire structure and causes the swelling of cement $[8,43]$. Or, in the case of mortar containing metakaolin, the portlandite $\mathrm{Ca}(\mathrm{OH})_{2}$ is be consumed by the pozzolanic reaction. Indeed, the chemical reaction that is established between the active metakaolin with calcium hydroxide $\mathrm{Ca}(\mathrm{OH})_{2}$, product at room temperature calcium silicate hydrate (C-S-H) additional, and) supplementary, and phases $\mathrm{C}_{4} \mathrm{AH}_{13}\left(2\left[\mathrm{Ca}_{2} \mathrm{Al}(\mathrm{OH})_{7} \cdot 3 \mathrm{H}_{2} \mathrm{O}\right]\right), \mathrm{C}_{2} \mathrm{ASH}_{8}$, and $\mathrm{C}_{3} \mathrm{AH}_{6}\left(\mathrm{Ca}_{3}\left[\mathrm{Al}(\mathrm{OH})_{6}\right]_{2}\right)$ [44,24]. The product formed depends primarily on the AS/CH $\left(\mathrm{Al}_{2} \mathrm{Si}_{2} \mathrm{O}_{7} / \mathrm{Ca}(\mathrm{OH})_{2}\right)$ ratio and the temperature of reaction [45-48]. With observed that (1) $\mathrm{Ca}(\mathrm{OH})_{2}$ was significantly small space with the age for all the rate of cement replacement by metakaolin $0,10 \%$, and $20 \%$; and (2) $20 \%$ of MK were required to remove all $\mathrm{Ca}(\mathrm{OH})_{2}$ entirely for concrete at 28 days. In the same way, Others study have shown, that between $30 \%$ and $40 \% \mathrm{Mk}$, is required to remove all $\mathrm{Ca}(\mathrm{OH})_{2}$ of the structure of metakaolin cement paste. At, the water - binder ratio $(\mathrm{w} / \mathrm{b})$ of 0.5 , when the paste lime during in the water, saturated with lime during 28 days [49]. Others similar studies, reported that $\mathrm{Ca}(\mathrm{OH})_{2}$ was quickly consumed, the microstructure was rich in calcium silicate hydrates (C-S-H) and stratlingite $\mathrm{C}_{2} \mathrm{ASH}_{8}\left(2 \mathrm{CaO} \cdot \mathrm{SiO}_{2} \cdot \mathrm{Al}_{2} \mathrm{O}_{3} \cdot 8 \mathrm{H}_{2} \mathrm{O}\right)$, and the distribution of the size of the pores moved towards smaller [16].

\section{Sulfate attack}

For resistance to the sulfate attack sodium sulfate $\mathrm{Na}_{2} \mathrm{SO}_{4}(5 \%)$, the results of the expansion of the mortars containing different content from cement substitution by metakaolin $5 \%, 10 \%, 15 \%$ and $20 \%$ are shown in Figure 6. It clear to noticed, that contrary to the cement without metakaolin the mortars containing metakaolin have shown a better resistance to the solution sodium sulfate $\mathrm{Na}_{2} \mathrm{SO}_{4}$. It can note a reduction in the expansion of the mortars which was proportional to the cement replacement level, by metakaolin. At 180 days of exposure, the sodium sulfate solution the mortar without metakaolin has produced an expansion of order $0.103 \%$ which slightly exceeds the limit of maximum expansion of $0.10 \%$ to be reached at the six months, recommended in standard ASTM C1012. While the mortars containing $5 \%$ and $10 \%$ of metakaolin exhibited expansions of $0.084 \%, 0.078 \%$ respectively less than $0.10 \%$ expansions at 180 days prescribed by standard ASTM C1012, indicating a moderated resistance to sulfate attack. Whereas, the other mortar containing higher metakaolin level, exhibited little expansion largely below the limit prescribed by the standard $0.059 \%$ and $0.042 \%$ respectively for the mortars containing $15 \%$ and
$20 \%$ of metakaolin indicated high resistance to sulfate attack, according to Standard ASTM C1012. Moreover, no sign of deterioration after 180 days of exposure in sodium sulfate solution. This improvement of resistance to the attack by sodium sulfate in the presence of the metakaolin the is attributed mainly to the reduction of the permeability of these mixtures, and of the decrease in the content of hydroxide of calcium $\mathrm{Ca}(\mathrm{OH})_{2}$ which is considered the most vulnerable elements in the cement matrix. Indeed, the ions sodium sulfate is less aggressive at the $(\mathrm{C}-\mathrm{S}-\mathrm{H})$, than the magnesium sulfate. The interaction between the portlandite and sodium sulfate has the secondary gypsum formation but also the formation hydroxide of sodium $(\mathrm{NaOH})$ which causes of stabilizes formation $(\mathrm{C}-\mathrm{S}-\mathrm{H})$, which caused it possible to decrease the processes of deterioration and transfers of ions within the cement matrix. Moreover, the pozzolanic reaction of metakaolin makes it possible to reduce the content of portlandite which is responsible for the formation for secondary gypsum $\left(\mathrm{CaSO}_{4} \cdot 2 \mathrm{H}_{2} \mathrm{O}\right)$ and ettringite $\left(3 \mathrm{CaO} \cdot \mathrm{Al}_{2} \mathrm{O}_{3} \cdot 3 \mathrm{CaSO}_{4} \cdot 32 \mathrm{H}_{2} \mathrm{O}\right)$ in the presence of the ions sulfate [54-57]. However, others similar studies rapport that the metakaolin decrease not only the quantity of free lime, but also those of aluminates available in the interstitial solution [29]. Combined with that, the densification of the cement matrix by the metakaolin led to the reduction in its permeability and its diffusivity significantly increases the resistance of the concrete to the migration of the ions sulfates. Furthermore, the results of this study are agree with the findings with other similar studies, showing that the mortars containing pozzolans almost do not present dimensional variations, whereas the mortar which contained $100 \%$ cement Portland cement expanded in the following way. The mortar which has the best resistance is that which contained $15 \%$ of metakaolin, thus confirming the effectiveness of metakaolin to resistance to sulfate of sodium [30]. Similarly, studies have conducted on the two types of cement, high $\mathrm{C}_{3} \mathrm{~A}$, and intermediate $\mathrm{C}_{3} \mathrm{~A}$ content; they reported that expansion decreased systematically with the increase in

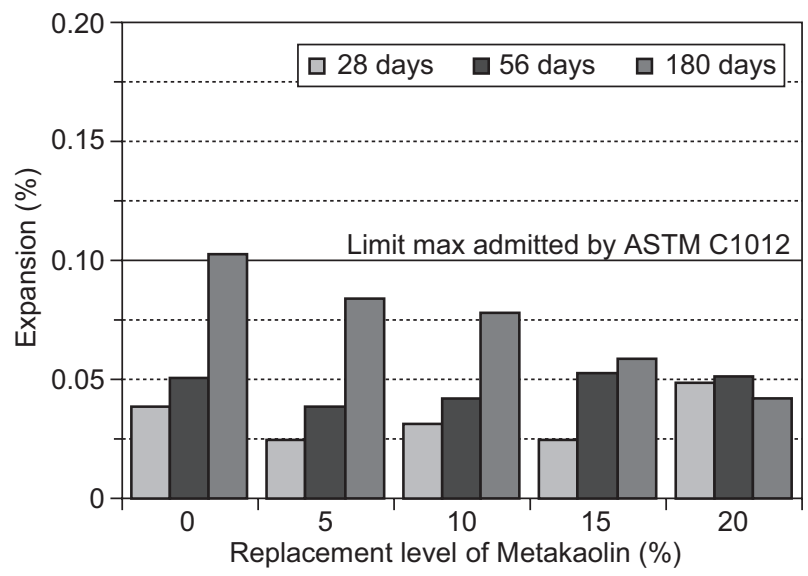

Figure 6. Expansion of mortar immersed in $\mathrm{Na}_{2} \mathrm{SO}_{4}$ solution. 
MK content for both types of cement. [28]. According to the authors, reduction in $\mathrm{CH}$ content is considered to be the principal factor by which $\mathrm{MK}$ improves sulfate resistance, and it suggested that the nature of the sulfate containing reaction product formed at high MK levels and low $\mathrm{CH}$ contents is different from that formed at low MK levels and consequently higher $\mathrm{CH}$ contents.

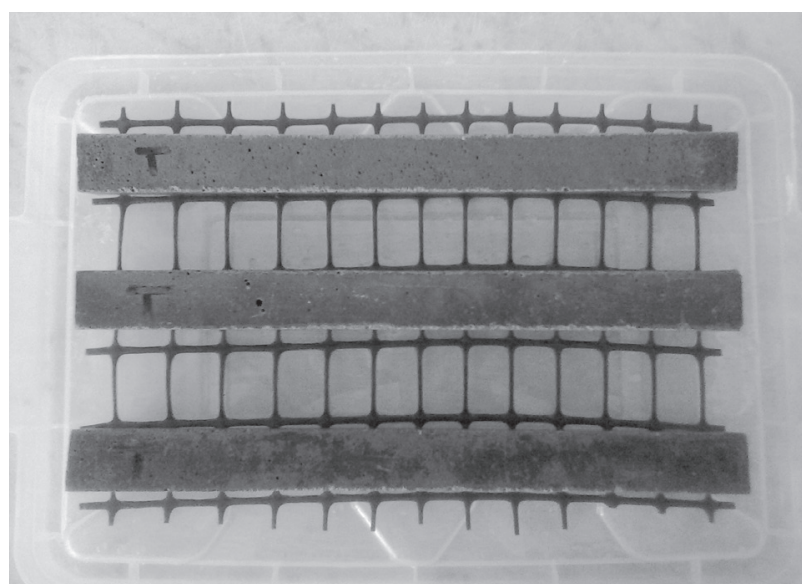

a) MK0

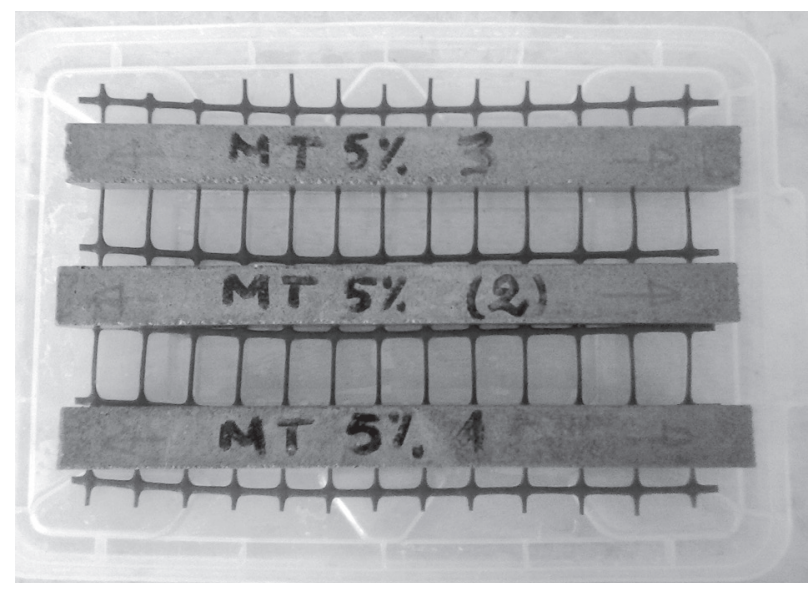

b) MK5

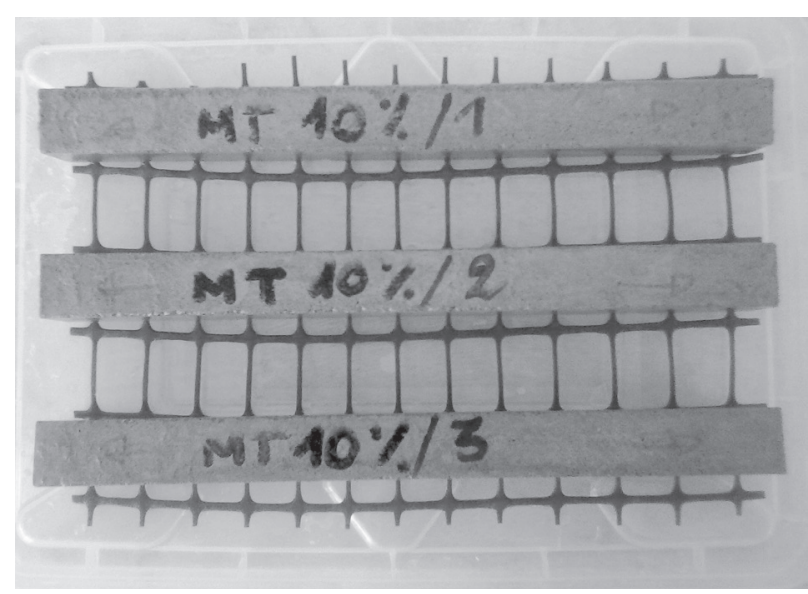

c) MK10

\section{CONCLUSIONS}

In this study, the effect of metakaolin as supplementary cementing materials on mechanical properties and durability of cement and mortars was investigated. After discussing the results, the following conclusions can be drawn:

The study showed that the MK contributed a significant increase the compressive strengths when used up to $20 \%$. Depending essentially, on replacement level of $\mathrm{MK}, \mathrm{w} / \mathrm{cm}$ ratio, and testing age. It is also noticed that the replacement of cement by $10 \%$ metakaolin gives the highest strengths result at the short-term when compared to other replacement levels, and highest strengths result for replacement of cement by $15 \%$ and $20 \%$ metakaolin at later ages.

The study showed that the compressive strength of all pastes mixtures is increased considerably, at any age by reducing the water content at the lower water to binder ratio.

The study showed that the mortar with MK exhibited remarkably lower shrinkage in comparison to the plain mortar without MK. The reduction being greater

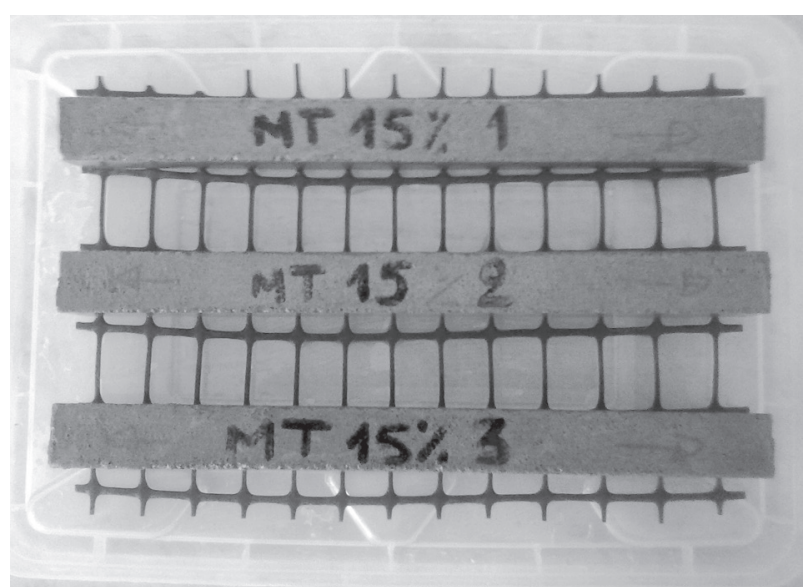

d) MK15

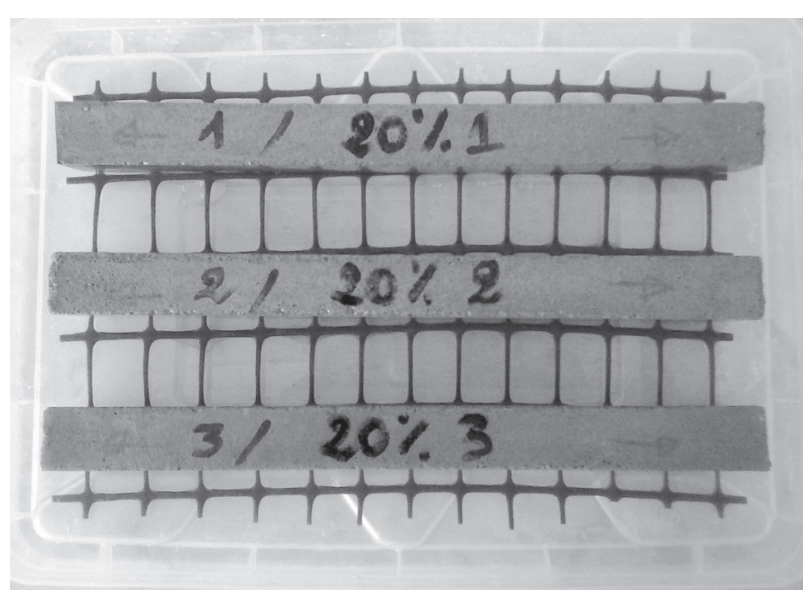

e) MK20

Figure 7. Specimens mortar exposed to $5 \%$ sodium sulfate solution for 180 days. 
at higher replacement levels, on another hand, the reduction of shrinkage for the long term up 120 days does not appear to be influenced by replacement level.

The study showed that the mortars containing metakaolin revealed an excellent performance of swelling to water, then mortar without metakaolin, it noticed that the increase in the level replacement of cement by metakaolin generates an increase in swelling. However, the swelling rates of the mortars had a decreasing tendency with increased time, particularly for the MK mortars.

The addition of MK as a partial cement replacement material provided an excellent improvement in resistance to the sodium sulfate $\mathrm{Na}_{2} \mathrm{SO}_{4}$. The resistance to the sulfate increased substantially with increasing replacement level of MK. The better resulted was obtunded for the highlevel MK replacement especially at a replacement level of $20 \% \mathrm{MK}$.

\section{Acknowledgments}

The authors would like to thank the members of the laboratory of civil engineering Department, University souk ahras and research laboratory civil engineering, University of biskra during the laboratory phase of the study.

\section{REFERENCES}

1. Tagnit H.A. (2006): Note de cours GCI 710 Liants Hydrauliques, Université de Sherbrooke, Québec, Canada.

2. Scrivener K.L., Kirkpatrick R.J. (2007): Innovation in use and research on cementitious material. Cement and Concrete Research, 38(2), 128-136. doi:10.1016/j.cemconres.2007.09.025

3. Rashad A.M. (2013): Metakaolin as cementitious material: history, scours, production and composition a comprehensive overview, Construction and Building Materials, 41, 303-318. doi:10.1016/j.conbuildmat.2012.12.001

4. Park S.S., Kang H.Y. (2008): Characterization of fly ash-pastes synthesized at different activator conditions. Korean Journal of Chemical Engineering, 25(1), 78-83. doi:10.1007/s11814-008-0013-6

5. Rashad A.M, Sayieda Z.R. (2011): The effect of activator concentration on the residual strength of alkali-activated fly ash pastes subjected to thermal load, Construction and Building Materials, 25, 3098-3107. doi:10.1016/j. conbuildmat.2010.12.044

6. Salhi K., Mezghiche B. (2011): Effects of slag of blast furnace and sand of dune on durability of mortar and concrete. World Journal of Engineering, 8(1), 23-28.

7. Salhi K., Mezghiche B. (2010): Effects of Sand of Dune and Granulated Slag on the Properties of Cement, The International Review of Civil Engineering (I.RE.C.E).

8. Salhi K., Mezghiche B. (2009): Etude de durabilité de mortier et béton contenant de ciment avec ajout de laitier et sable de Dune, in: $1^{\text {st }}$ International Conference on Sustainable Built Environment Infrastructures in Developing Countries ENSET Oran, Algeria, Oct. 12-14.
9. Kocaba V. (2009): Development and evaluation of methods to follow microstructural development of cementitious systems including slags. Materials Department. EPFL, Lausanne. doi:10.5075/epfl-thesis-4523

10. Lothenbach B., Scrivener K., Hooton R. D. (2010): Supplementary cementitious materials. Cement and Concrete Research, 41(12), 1244-1256. doi:10.1016/j.cemconres. 2010.12.001

11. Richardson I. G., Groves G. W. (1997): The structure of the calcium silicate hydrate phases present in hardened pastes of white Portland cement blast-furnace slag blends. Journal of Materials Science, 32(18), 4793-4802. doi:10.1023/ A: 1018639232570

12. Neville A. M. (2002). Properties of concrete. London EN, Prentice Hall.

13. Hooton R. D. (1986): Permeabilidade and pore structure of cement pastes containing slag fly ash and silica fume, in: Blended Cement. ASTM Special Technical Publication, pp. 128-143. doi:10.1520/STP36395S

14. Mehta P. K. (1981): Sulfate Resistance in Blended Portland Cements Containing Pozzolans and Granulated Blast-Furnace Slag, in: Fifth International Symposium on Concrete Technology. Monterrey. pp. 35-50.

15. Al-Akhras N.M. (2006): Durability of metakaolin to sulfate attack. Cement and Concrete Research, 36(9), 1727-1734. doi: 10.1016/j.cemconres.2006.03.026

16. AmbroiseJ., Maximilien S., Pera J. (1994): Properties of metakaolin blended cements. Advanced Cement Based Materials, 1(4), 161-168. doi:10.1016/1065-7355(94)90007-8

17. Aquino W., Lange D.A., Olek D.A. (2001): The influence of metakaolin and silica fume on the chemistry of alkalisilica reaction products. Cement and Concrete Composites, 23(6); 485-493. doi:10.1016/S0958-9465(00)00096-2

18. Asbridge A.H., Walters G.V., Jones T.R. (1994): Ternary blended concretes-OPC/GGBFS/metakaolin, in: Denmark: Concrete across Borders, pp. 547-557.

19. Asbridge A.H., Chadbourn G.A., Page C.L. (2001): Effects of metakaolin and the interfacial transition zone on the diffusion of chloride ions through cement mortars. Cement and Concrete Research, 31 (11), 1567-1572. doi:10.1016/ S0008-8846(01)00598-1.

20. Asbridge A.H., Page C.L.,Page M.M. (2002): Effects of metakaolin, water/binder ratio and interfacial transition zones on the micro hardness of cement mortars. Cement and Concrete Research, 32(9), 1365-1369. doi:10.1016/ S0008-8846(02)00798-6

21. Badogiannis E., Papadakis V.G., Chaniotakis E., Tsivilis S. (2004): Exploitation of poor Greek kaolins: strength development of metakaolin concrete and evaluation by means of k-value. Cement and Concrete Research, 34(6), 1035-1041. doi:10.1016/j.cemconres.2003.11.014

22. Caldarone M.A., Gruber K.A., Burg R.G. (1994): HighReactivity Metakaolin (HRM): A New Generation Mineral Admixture for High Performance Concrete. Concrete International, 16(11), 37-41.

23. Wild S., Khatib JM., Jones A. (1996): Relative strength, pozzolanic activity and cement hydration in superplasticized metakaolin concrete. Cement and Concrete Research, 26, 1537-1544. doi:10.1016/0008-8846(96)00148-2

24. Zhang M.H., Malhotra V.M. (1995): Characteristics of a thermally activated aluminosilicate pozzolanic material ant its use in concrete. Cement and Concrete Research, 25, 1713-1725. doi:10.1016/0008-8846(95)00167-0 
25. Khatri R.P., Sirivivatnanon V., Yu L.K. (1997): Effect of curing on water permeability of concretes prepared with normal Portland cement and with slag and silica fume. Magazine of concrete research, 49(180), 167-172. doi:10.1680/macr.1997.49.180.167

26. Poon C.S., Azhar S., Anson M., Wong Y.L. (2003): Performance of metakaolin concrete at elevated temperatures. Cement and Concrete Composites, 25(1), 83-89. doi:10.1016/S0958-9465(01)00061-0

27. Batis G., Pantazopoulou P., Tsivilis S., Badogiannis E. (2005): The effect of metakaolin on the corrosion behavior of cements mortars. Cement and Concrete Composites, 27(1), 125-130. doi:10.1016/j.cemconcomp.2004.02.041

28. Khatib J.M., Wild S. (1998): Sulfate resistance of metakaolin mortar. Cement and Concrete Research, 28(1), 83-92. doi:10.1016/S0008-8846(97)00210-X

29. Sabir B.B., Wild S., Khatib J.M. (1996): On the workability and strength development of metakaolin concrete, in: Concrete for Environmental Enhancement and Protection, E\&FN Spon, pp. 651-656.

13. Bai J., Sabir J.J., Kinuthia J.M., Wild S. (2002): Metakaolin - Pulverized fuel ash - Portland cement binders and their role in mortar and concrete, in: Proceedings of Dundee Conference, pp.159-173.

31. Lawrence P., Cyr M., Ringot E. (2003): Mineral admixtures in mortars, effect of inert materials on short-term hydration. Cement and Concrete Research, 33(12), 39-47. doi:10.1016/ S0008-8846(03)00183-2

32. Lawrence P., Cyr M., Ringot E. (2005): Mineral admixtures in mortars, effect of type, amount and finesses of fine constituents on compressive strength. Cement and Concrete Research, 35(6), 1092-1105. doi:10.1016/j.cemconres. 2004.07.004

33. Cyr M., Lawrence P., Ringot E. (2005): Mineral admixtures in mortars, quantification of the physical effects of inert materials in relation on short-term hydration. Cement and Concrete Research, 35(4), 719-730. doi:10.1016/j.cemconres.2004.05.030

34. Cyr M., Lawrance P., Ringot E. (2006): Efficiency of mineral admixtures in mortars, quantification of physical and chemical effects of fine admixtures in relation with compressive strength. Cement and Concrete Research, 36(2), 264-277. doi:10.1016/j.cemconres.2005.07.001

35. Lino M., Miguel A., Rui F., Joaquim F. (1996): Influence of the cementitious paste composition on the E-modulus and heat of hydration evolutions. Cement and Concrete Research, 26(10), 1537-1544. doi:10.1016/j.cemconres.2011.03.008

36. Maria C.G., Juenger., Rafat S. (2015): Recent advances in understanding the role of supplementary cementitious materials in concrete. Cement and Concrete Research, 78, 71-80. doi:10.1016/j.cemconres.2015.03.018

37. Guettala S., Mezghiche B. (2011): Compressive strength and hydration with age of cement pastes containing dune sand. Construction and building materials, 25(3), 1263-1269. doi:10.1016/j.conbuildmat.2010.09.026

38. Brooks J.J., Johari M.M.A. (2001): Effect of metakaolin on creep and shrinkage of concrete. Cement and Concrete Composites, 23(6), 495-502. doi:10.1016/S0958-9465(00) 00095-0

39. Güneyisi E., Gesoğlu M., Mermerdaş K. (2008): Improving strength, drying shrinkage, and pore structure of concrete using metakaolin. Materials and Structures, 41(5), 937-949. doi:10.1617/s11527-007-9296-Z

40. Jianyong L., Yan Y. A . (2001): Study on creep and drying shrinkage of high performance concrete. Cement and Concrete Research, 31, 1203-1206. doi:10.1016/S00088846(01)00539-7
41. Power T.C. (1959): Causes and control of volume change. Journal of the PCA Research and Development Laboratories, 1(1), 29-39.

42. Changling H., Osbaeck B., Makovicky E. (1995): Pozzolanic reaction of six principal clay minerals: activation reactivity assessments and technological effects. Cement and Concrete Research, 25(8), 1691-1702. doi:10.1016/0008-8846 (95)00165-4

43. Dupain R., Lanchon R., Saint-Arroman J.C. (2004): Granulats, sols, ciments et bétons: caractérisation des matériaux de génie civil par les essais de laboratoire: terminale STI Génie civil, BTS bâtiment, BTS travaux publics, DUT Génie civil, MST Génie civil, Ecoles d'ingénieurs. Casteilla.

44. Laakri M., Oudjit M., Abdelli K. (2014): Volumetric Variation and Rheology of Cement Based Mineral Additions (Blast Furnace Slag and Silica Fume), Journal of Civil Engineering and Architecture, 8, 207-212.

45. Murat M. (1983): Hydration reaction and hardening of calcined clays and related mineral-Preliminary investigations on metakaolin, Cement and Concrete Research, 13(2), 259-266. doi:10.1016/0008-8846(83)90109-6

46. Wild S., Khatib J., Roose J.L.(1998): Chemical and autogenous shrinkage of Portland cement metakaolin pastes. Advances in Cement Research, 10(3), 109-119. doi:10.1680/ adcr.1998.10.3.109

47. Kinuthia J.M., Wild S., Sabir B.B., Bai J. (2000): Selfcompensating autogenous shrinkage in Portland cementmetakaolin -fly ash pastes. Advances in Cement Research, 12(1), 35-43. doi:10.1680/adcr.2000.12.1.35

48. Kostuch J.A., Walters V., Jones T.R. (2000). High performance concretes incorporating metakaolin: a review. Concrete, 2(1993), 1799-1811.

49. Oriol M., Pera J. (1995): Pozzolanic activity of metakaolin under microwave treatment, Cement and Concrete Research, 25(2), 265-270. doi:10.1016/0008-8846(95)00007-0

50. Mazloom M., Ramezanianpour A.A., Brooks J.J. (2004): Effect of silica fume on mechanical properties of highstrength concrete. Cement and Concrete Composites, 26(4), 347-357. doi:10.1016/S0958-9465(03)00017-9

51. Rao G.A. (1998): Influence of silica fume replacement of cement on expansion and drying shrinkage. Cement and Concrete Research, 28, 1505-1509. doi:10.1016/S00088846(98)00127-6

52. Fattuhi N.I., Al-Khaiat H. (1999): Shrinkage of concrete exposed to hotand arid climate. Journal of Materials in Civil Engineering, 11(1), 66-75. doi:10.1061/(ASCE)08991561(1999)11:1(66)

53. Shah S.P., Ahmad S.H. (1994). High Performance Concrete and Applications. Edward Arnold, London.

54. Neville A. (2004): The confused world of sulfate attack on concrete. Cement and Concrete Research, 34, 1275-1296. doi:10.1016/j.cemconres.2004.04.004

55. Duval R ., Hornain. H. (1992) : La durabilité du béton visà-vis des eaux agressives. In Baron J., Olivier J.P. (ed.): $L a$ durabilité des bétons. Presses de l'École nationale des ponts et Chaussées, pp. 351-391.

56. Cohen M. D., Mather B. (1991): Sulfate attack on concrete research needs. Materials Journal, 88(1), 62-69.

57. Mehta P.K. (1973): Mechanism of Expansion Associated with Ettringite Formation. Cement and Concrete Research, 3, 1-6. doi:10.1016/0008-8846(73)90056-2

58. Poon C.S., Kou S.C., Lam L.(2006): Compressive strength, chloride diffusivity and pore structure of high performance metakaolin and silica fume concrete. Construction and building materials, 20(10), 858-865. doi:10. 1016/j. conbuildmat.2005.07.001 